\title{
In Defense of Theory and Analysis: A Critical Evaluation of the Discipline and Its Application to Bartók's Musical Language
}

\author{
Em defesa da Teoria e Análise: Uma Avaliação Crítica da \\ Disciplina e sua Aplicação à Linguagem Musical de Bartók
}

\author{
Elliott Antokoletz \\ University of Texas at Austin, USA \\ antokoletz@utexas.edu
}

Abstract: This paper defends an evaluation of Bartók's music based on analytical procedures that use abstract theoretical concepts instead of, as advocate some scholars like László Somfai, restrict it to the scrutiny of compositional sketches and ethnomusicological influences. The analytical contributions of Roy Travis, Malcolm Gillies, Erno Lendvai, János Kárpáti, Colin Mason, Allen Forte and Richard Cohn, among others, are evaluated in order to introduce an original model that proposes a nontraditional tonal system based on the interval cycles and inversional symmetry, following some of George Perle's propositions.

Keywords: music analysis; music theory; Bartók; interval cycles; inversional symmetry; atonal tonality.

Resumo: Este artigo defende uma avaliação da música de Bartók baseada em procedimentos analíticos que utilizem conceitos teóricos em vez de, como advogam alguns acadêmicos como László Somfai, restringi-la ao escrutínio de manuscritos do compositor e influências etnomusicológicas. As contribuições analíticas de Roy Travis, Malcolm Gillies, Erno Lendvai, János Kárpáti, Colin Mason, Allen Forte e Richard Cohn, entre outros, são avaliadas com o propósito de introduzir um modelo original que propõe um sistema tonal não-tradicional baseado em ciclos intervalares e simetria inversional, seguindo algumas das proposições de George Perle.

Palavras-chave: análise musical; teoria musical; Bartók; ciclos intervalares; simetria inversional; tonalidade atonal. 


\section{1 - Introduction}

On occasion, certain Bartók scholars have brought into question the authenticity of the theoretic-analytical discipline as a primary means for understanding Bartók's musical language. These scholars have advocated - sometimes almost to the point of exclusivity - Bartók's Eastern European folk-music sources and his compositional sketches as the only authentic means for investigating his musical idiom. For instance, László Somfai (Director of the Budapest Bartók Archívum) attributes a lack of authenticity to the theoretic-analytical discipline (Somfai 1996, p.10). He quotes Bartók to prove that intuition rather than conscious theory was the basis for Bartók's compositional approach. However, the next sentence that actually appears in Bartók's original statement (Bartók 1976, p.376): "Now that the greatest part of my work has already been written, certain general tendencies appear - general formulas from which theories can be deduced," is removed by Somfai from its proper context in his indented quote and placed in the preceding discussion on the same page. Somfai's displacement of this sentence deemphasizes the significance of Bartók's own assertion that theoretical explanations can be deduced in his music. In attributing a lack of authenticity to theoretic-analysis, Somfai ignores the possibility that, in addition to the study of the manuscript sources, the intimate involvement with the music required by analysis might give meaning and provide more satisfactory musical explanations. Somfai's almost exclusive focus on the importance of the manuscripts themselves limits the usefulness of his otherwise thorough coverage of the source materials. On the other hand, Malcolm Gillies states: "the published score rarely provides a complete picture, being a final compromise between many different compositional, publishing, editorial and performing factors. Only by tracing the path from sketch to score can the relationship between notation and tonal structure be investigated fully satisfactorily" (Gillies 1989, p.10). While Gillies's assertion has its merits, it does seem somewhat overstated. More directly and problematically, in his panel commentary at the 1995 Bartók Colloquium in Szombathely, Hungary, Gillies placed the study of the folk-music sources and sketches above the discipline of theoretic-analysis according to his hierarchical ordering from "authentic and semi-authentic to inauthentic." We must assert that the final composition is as much a primary source as are the sketches or folkmusic materials. In the final assessment, theoretic-analytical scrutiny can tell us in more definitive ways about the composer's artistic thought than the preliminary stages of the compositional process: to use a truism, it is the composer's final decision that must be considered to be of the utmost importance in the fulfillment and ultimate meaning of the artwork. This does not mean that the exclusive study of the published score is entirely adequate or even desirable, since we can benefit more fully from scrutiny of all stages of the compositional 
process and the external folk sources that Bartók absorbed into his compositions. To label the discipline of theoretic-analysis as "inauthentic" seems arbitrary.

In fact, Bartók's compositions sprang from the same general realm of art music as that of Debussy, Stravinsky, Scriabin, members of the Vienna Schoenberg circle, and other composers of the early twentieth century. Notwithstanding the important role that Eastern European folk music played in Bartók's compositional efforts to establish a musical mother tongue, the folk sources are essentially external to the composition, and so, they cannot play a primary role in understanding the internal workings of his musical language per se. Furthermore, in the absence of some integrated theoretical perception of the musical artifact itself, the scrutiny of Bartók's compositional sketches for the purpose of elucidating aspects of the musical language seems a relatively autonomous and vacuous endeavor.

Meaningful identification of the principles of pitch construction and harmonic progression in Bartók's music has been the concern of theorists from the time of the composer's death in the mid-1940s. The emergence of diverse approaches to the study of Bartók's musical language may be due in part to global separation and linguistic differences, which have fostered distinct "schools" of theory and analysis. However, the complexity and diversity of the musical language itself may be the most significant factor in the development of internationally diverse and often contradictory approaches to its study. The intention in this essay is to evaluate divergent theoretic-analytical approaches to Bartók's music and to advocate a more integrated theoretical perspective in view of Bartók's own stated conception of his music.

One of the main gaps that has existed in determining the primary means of pitch organization in Bartók's music is that there has been no theory comparable to that of the traditional tonal system, which draws together all pitch formations in his music under one coherent set of principles. Yet, one senses in Bartók's music a remarkable harmonic integration existing between the diatonic and chromatic spheres. Bartók stated, in connection with the principles of diatonic extension of chromatic themes and the reverse, chromatic compression of diatonic themes that "this circumstance is very good indeed, because we will get variety on the one hand, but the unity will remain undestroyed because of the hidden relation between the two forms" (Bartók 1976, p.381).

Diverse, often conflicting interpretations characterize the world of Bartók theory and analysis. Scholars have developed approaches to Bartók's pitch organization ranging from the more traditional concepts to those that can only belong to the twentieth century ${ }^{1}$. Studies include principles of traditional

\footnotetext{
${ }^{1}$ Several of these approaches were discussed in Antokoletz 1975, Chap. VI; see also Antokoletz 1982 p.67-74, for a selection of briefer discussions.
} 
harmonic function, modality, polymodal chromaticism, polytonality, pitch-class set theory, atonality, and a new kind of tonality derived from the joining of the concepts of the interval cycle and inversional symmetry. Although many important insights have emerged from these studies, they generally apply to isolated instances and do not encompass the broad spectrum of his musical language. Considering the complexity and variety of Bartók's pitch structures and progressions, an isolated insight into some single excerpt brings with it the risk of oversimplification and distortion Antokoletz 1982, p.xi). Let us examine the various representative theories beginning with those founded on the more traditional concepts.

\section{2 - Schenkerian methodized approach to tonal structure and harmonic progression}

Some theorists have attempted to explain tonal centricity in Bartók's music according to traditional tonal principles, and to define these pitch relations according to pre-established concepts and terminology. Roy Travis, in his study of the first movement of the Fourth String Quartet (Travis 1970, p. 298-371), has adopted the Schenkerian concept of contrapuntal prolongation of subdominant, dominant, and tonic structural areas (Ex. 1a and 1b). To analyze a work according to these traditional tonal principles that work must consist of triads derived from the major-minor scale system. One reason is that the third degree of the dominant triad is the leading tone in a major or minor key, and this tone is largely responsible for the pull of the dominant triad to that of the tonic. There is no evidence that such voice-leading functions occur in Bartók's music, except in certain isolated cases.

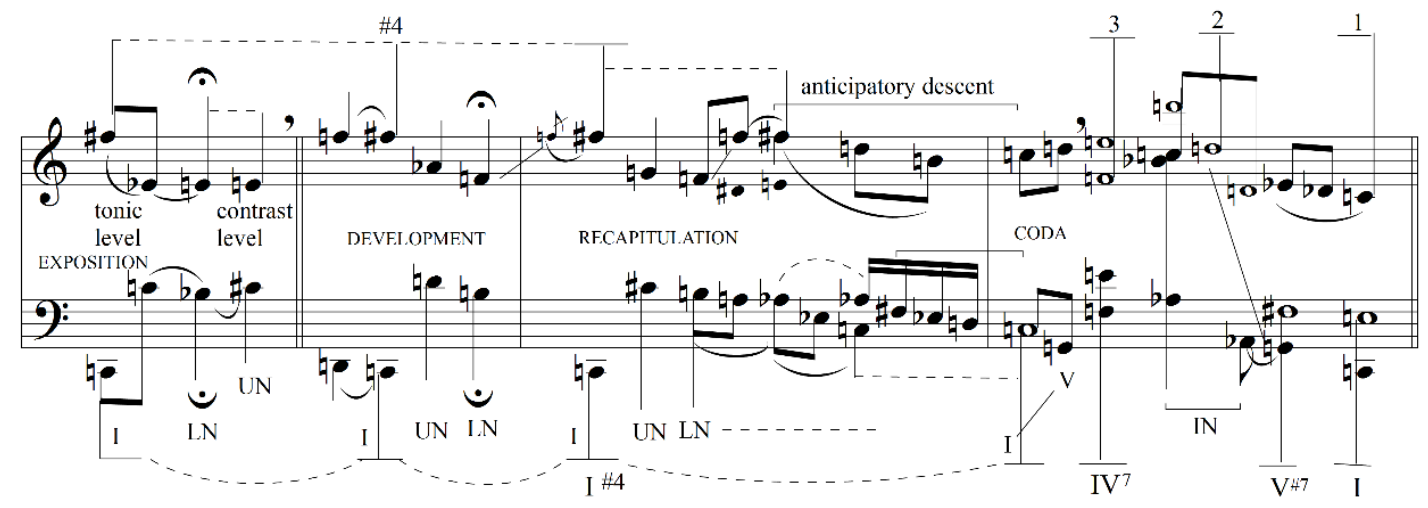

Example 1a: Schenkerian background graph by Roy Travis of the structure and chief prolongation, formally articulated in Movement I of Bartók's Fourth String Quartet 


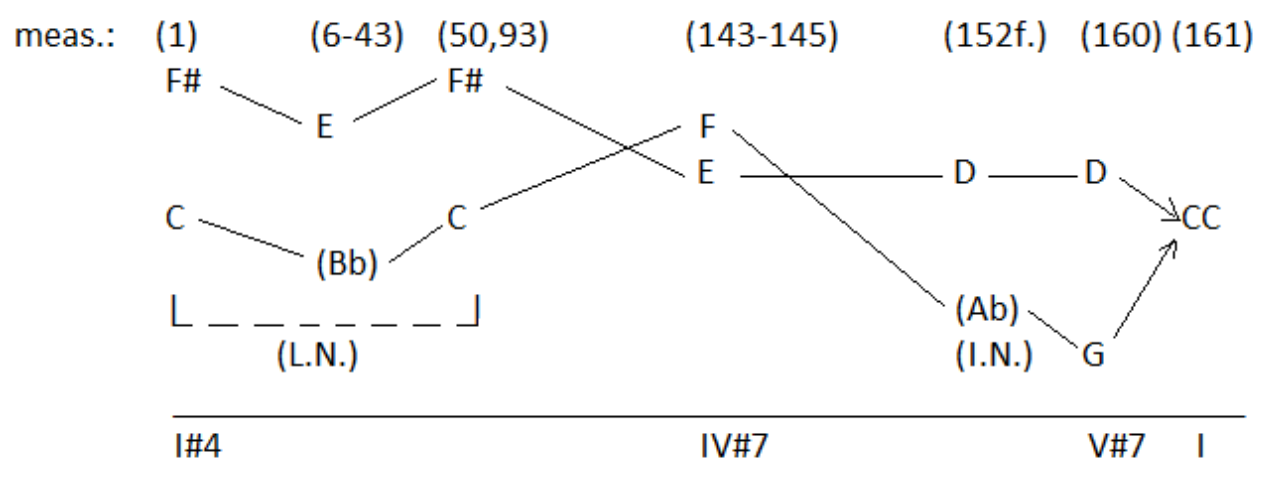

Example 1b: Summary of voice leading in the top- and bottom- voice structures of Example 1a, with final intersection at C-C

Travis has nevertheless attempted to establish, according to the Schenkerian methodized approach, a traditional tonal organization in the first movement of the quartet. He does acknowledge that the quartet is not triadic, and so he invokes the notion of a "dissonant tonic sonority" instead (Travis 1970, p.299)2. It should be noted at the outset that Travis's notion of an expanded "tonic sonority" is contrary to Bartók's own expressed tonal conception. Bartók refuted the notion of an aural perception of the "multiple-centred structures" present within the bitonal and polytonal formations admitted by Travis's "tonal" definition. In his background graph of the movement, Travis implies that traditional triadic structures, which are basically comprised of perfect fifths and major and minor thirds, are often replaced by tritone-bounded chords filled with various intervals. According to Travis, most of the movement to the closing idea of the recapitulation (mm. 1-126) is a prolongation of the dissonant tonic sonority, C-F\#. He illustrates in his background graph, however, that the main cadential area of the movement (coda, mm. 134-161) is based on an outline of traditional structural chords (IV7 at mm. 134-45, V\#7 at m. 160, and I at m. 161).

Travis further attempts to reconcile Bartók's harmonic materials with those of the traditional tonal system by considering the tritone as a fundamental chordal structure analogous to the perfect fifth of the triad and set within a context based on traditional harmonic-root associations. He illustrates that the tritone-bounded chord, Bb-C-D-E (mm. 6-43), functions as a lower neighbor to the structural tonic-tritone C-F\# (mm. 1-5 and m. 50), while in vn I and va (m. 22) the double tritones (G\#-D/C\#-G) form an embellishing chord (Ex. 2).

\footnotetext{
${ }^{2}$ Malcolm Gillies appropriately contrasts Travis's notion of an expanded "tonic sonority" against Bartók's own expressed tonal conception (Gillies 1989, p.15). Bartók also refuted the notion of an aural perception of the "multiple-centred structures" present within the bitonal and polytonal formations admitted by Travis's "tonal" definition. See also Ernst Oster's reaction, in "Re: A New Concept of Tonality?", Journal of Music Theory 4 (1960): 85-98.
} 


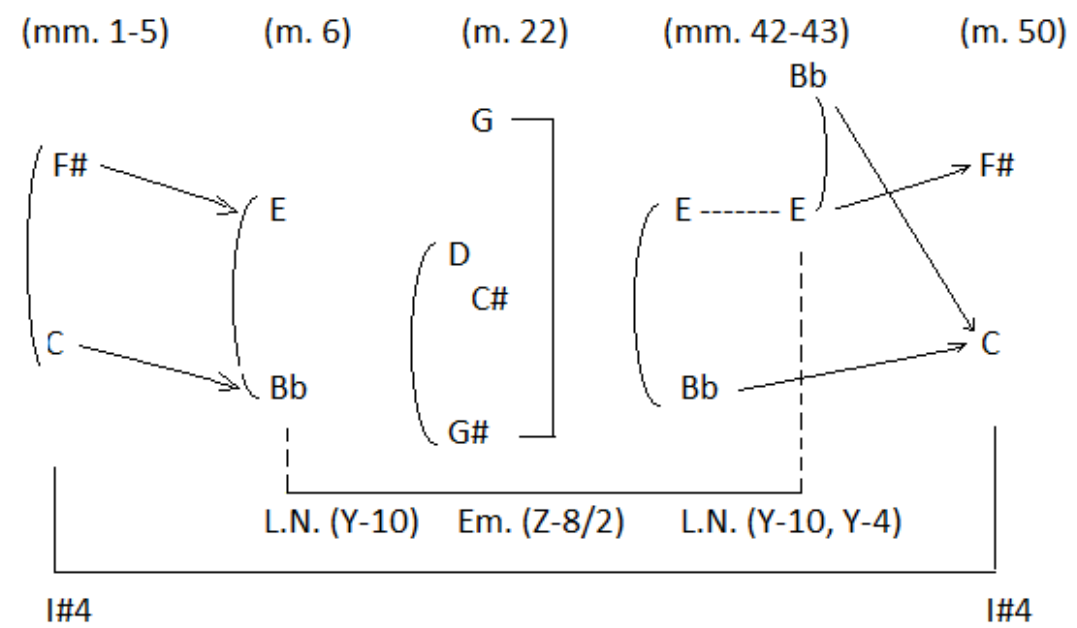

Example 2: Neighbor and embellishing chords (mm. 6-43) to the tonic-tritone C-F\# (mm. 1-5 and m.50), according to Travis

A contradiction arises in Example 1 when Travis analyzes the tritone boundary of one of the whole-tone tetrachords, Ab-Bb-C-D (mm. 152-6 of the coda), as dissonant and unstable (Travis 1970, p.308). Based on his general consideration of the tritone as a fundamental chordal structure analogous to the perfect fifth of a traditional major or minor triad, $\mathrm{Ab}$ and $\mathrm{D}$ must be interpreted as principal tones here. However, in Example 1, Travis conveniently reinterprets the tritone boundary (Ab-D) now as being in need of resolution, the $\mathrm{Ab}$ functioning as an incomplete neighbor to the $\operatorname{root}(\mathrm{G})$ of the structural $\mathrm{V} \# 7$, while the $\mathrm{D}$ is retained as a principal tone in the latter (Ex. 3). The tritone boundary (Ab-D) of the whole-tone tetrachord (at mm. 152ff.) is simultaneously considered by Travis, therefore, as a fundamental chordal structure (demonstrated in Ex. 2 by the analysis of the tritones) and as a dissonant interval that ultimately resolves (at $\mathrm{m}$. 160) to the perfect fifth of $\mathrm{V}^{7}$ (Ex. 3). This interpretation suggests that Travis still considers the fifth of the traditional triad, of which there is actually not a single occurrence in the work, as basic to Bartók's harmonic language.

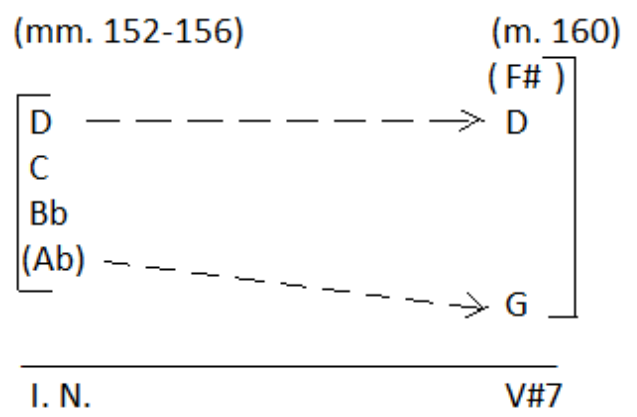

Example 3: Incomplete neighbor (mm. 152-156) to structural V\#7, according to Travis 
Nevertheless, Travis attempts to show how the overall bottom voice structure (Ex. 4) supports a background-level prolongation of a descending whole-tone tetrachord (F\#-E-D-C). While such an analysis on the purely contrapuntal level is perhaps somewhat more plausible in showing how $\mathrm{C}$ is established as the primary tonal center, the lack of triadic harmony above each bass note renders this linear interpretation somewhat moot. For instance, the area of IV\#7 (mm. 134-145) is assigned to the ostinato F-E even though there is no contextual evidence to assume it as part of a larger tertian construction (F-A-CE).

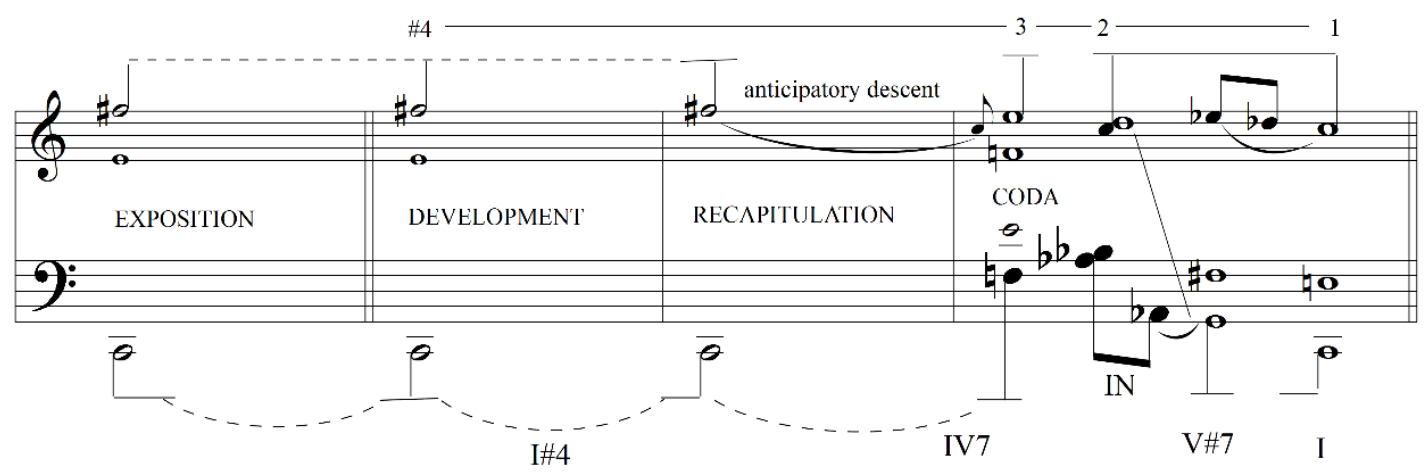

Example 4: Structure, formally articulated, according to Travis

\section{3 - Interval Construction and Tonal Functions based on "Golden Section," "Acoustic," and"Polar-Axis" systems}

The realization by other theorists that Bartók's diverse pitch formations do not belong to any uniform set of traditional rules has urged them to join traditional principles with a chromatic conception based on the equalization of the twelve tones. Many Europeans and Americans have espoused the theories of the Hungarian scholar, Erno Lendvai ${ }^{3}$. His basic premises for categorizing

\footnotetext{
3 Some of these include Hilda Gervers, "Béla Bartók's Five Songs (Öt dal) Opus 15," Music Review 30/4 (November 1969) p. 291-9; Tibor Bachmann and Peter J. Bachmann, "An Analysis of Béla Bartók's Music Through Fibonaccian Numbers and the Golden Mean," The Musical Quarterly 65/1 (January 1979) p. 72-82; László Somfai and Vera Lampert, "Bartók, Béla," The New Grove Dictionary of Music and Musicians, ed. Stanley Sadie, 6th edition (London: Macmillin, 1980), pp. 197-224, 2078 especially, and 211; Oszkár Frank, Bevezeto... Bartók Mikrokozmoszának világába [Introduction to the world of Bartók's Mikrokosmos] (Budapest: Zenemu...kiadó, 1977); Miklós Szabó, Bartók Béla kórusmu ...vei [Béla Bartók's choral works] (Budapest: Zenemu...kiadó, 1985); and others. Among the earliest to discuss Golden Section proportions in music from the time of Bach to Bartók's Violin Concerto, and String Quartets Nos. V and VI, was J.H. Douglas Webster, in "Golden-Mean Form in Music," Music and Letters 31 (1950) p. 238-48.
} 
chordal properties and functions are found in "Golden Section" and "Acoustic" scales and his "Polar-Axis" System, the latter of which (Ex. 5a and 5b) assumes tonic, dominant, and subdominant functions for the components of the three minor-third (interval-3) cycles, respectively. Again, without the traditional triadic constructions above the bass tones, the assignment of traditional harmonic functions to Bartók's chords seems arbitrary.

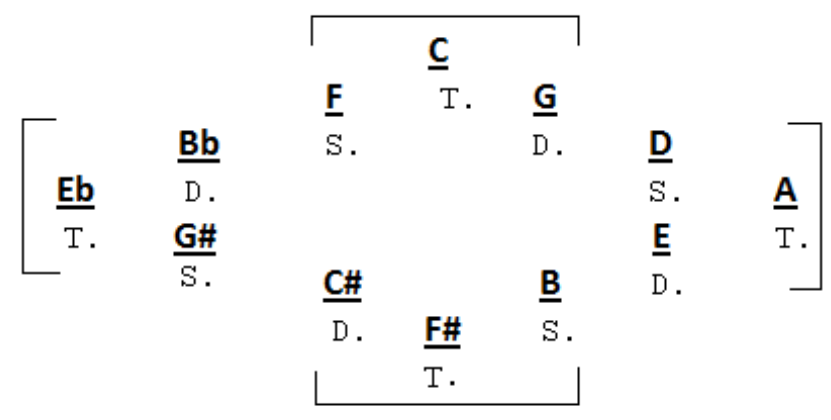

Example 5a: Lendvai's "polar-axis" system (circle of fifths model)

Subdominant axes

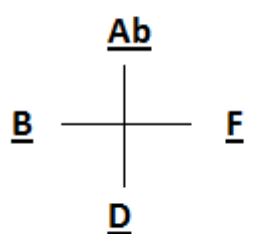

$\underline{\mathrm{D}}$ $\underline{\text { Tonic Axes }}$

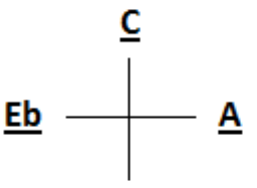

F\#
Dominant Axes

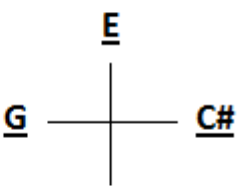

$\underline{B b}$

Example 5b: Lendvai's "polar-axis" system (S,T,D model)

Lendvai's harmonic analyses of Bartók's music imply a direct connection between traditional tonal/harmonic functions and the system based on equal subdivisions of the octave ${ }^{4}$. He suggests that such key schemes as C-E-Ab-C in the four movements of Brahm's First Symphony represent (through tone substitution) the traditional harmonic relationships of tonic-dominantsubdominant-tonic. This is similar to the key outline in four of the five movements of Bartók's Fourth Quartet. His assumption that the keys in this sequence have "functional interconnection" in the traditional sense is hardly plausible, since this specific sequence (tonic-dominant-subdominant-tonic) rarely, if ever, occurs in traditional diatonic music.

4 See Erno Lendvai 1971, which represents the most comprehensive English-language presentation of Lendvai's theories of Bartók's music. For his other writings on the subject see the annotated listings in Antokoletz, Béla Bartók: A Guide to Research (New York and London: Garland Publishing, Inc., 1988), Nos. 464-470 especially, and 580. 
By dividing the circle of fifths into these three harmonic areas, S, T, D (Ex. $5 a)$, we find that the tonic $C$, dominant $E$, and subdominant $A b$ supposedly have the same functions as their tritone equivalents and minor thirds. Each of these three functions therefore has four poles (Ex. 5b). Thus, while each pair of axes subdivides the octave equally into minor thirds, the entire "polar-axis system" is based, according to Lendvai, on a hierarchy of traditional tonal relationships. In this system, Lendvai deals only with the root functions of traditional harmony, neither explaining what kinds of chords may be built on these roots nor how the root of a chord is determined.

The Golden Section (G.S.) formula (expressed in the equations of the Fibonacci series, $1+1=2,1+2=3,2+3=5,3+5=8$, etc.), which underlies any group of three adjacent numbers (intervals) in this series, is the basis of Lendvai's chromatic (G.S.) system. Any chord or linear structure, in which the boundary interval is subdivided according to these proportions of the Golden Section (as shown in Ex. 6), is part of Lendvai's chromatic system. Lendvai also considers G.S. interval proportions as the basis for pentatony (Lendvai 1971, p. 48, fig. 42).

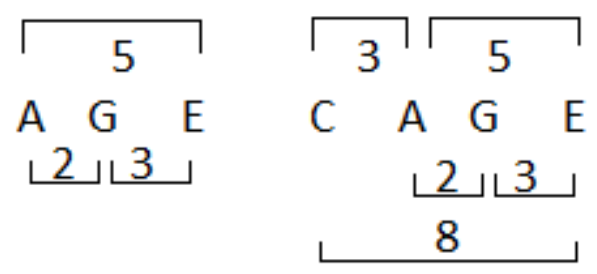

Example 6: Golden Section (G.S.) as the basis of pentatony. "Chromatic" system contains intervallic relationships derived from the "Golden Section", that is, intervals based on the geometrically progressing Fibonacci numbers: 1, 1, 2, 3, 5, 8, 13, 21, etc. Each number represents an interval.

If we were to assign G.S. and Acoustic labels to all the chords in a given Bartók work, we would find no discernible pattern either locally or in relation to the large-scale structure and design. On the other hand, Lendvai's application of the G.S. system and the Fibonacci series to the formal proportions of Bartók's music does appear to be a significant contribution to our understanding of form in many of Bartók's compositions.

\section{4 - Phenomenon of "Mistuning", Bitonality, and Polytonality}

János Kárpáti's discussion of "the phenomenon of mistuning" (Kárpáti 1967) points to a significant theory of Bartók's pitch relations, which seems to accord well with the composer's own stated premises regarding "diatonic extension" and "chromatic compression." A fundamental premise of Kárpáti's 
theory of "mistuning," which served Bartók's "distorting purposes," is the primacy of the fifth-octave relations inherent in traditional tonal/harmonic construction and functions of the major-minor scale system and in the nonfunctional diatonic modes that Bartók first found in Hungarian folk music. This basic structural premise convincingly points to the foundations of tonality as the point of departure for Bartók's more modernistic chromatic idiom. According to Kárpáti, "no matter how much the melody may be enriched by alteration, the perfect fifth-octave framework is permanent and virtually impassable. Bartók also approaches the problem from this angle--as is shown by the fact that perfect octave-fifth relations were by no means excluded from his theme writing, thus creating the specific meaning for the mistuned form" (Kárpáti 1975, p. 141).

Kárpáti points to basic sources for Bartók's "distortions" of this framework in Romanian and Arab folk music ${ }^{5}$. From these folk-music investigations, Bartók had discovered nondiatonic scales as the basis for melodies that have no perfect fifth or octave above the modal tonic, but reveal instead the frequent occurrence of the diminished or augmented fifth, which Kárpáti sees as mistunings of the perfect fifth.

Kárpáti's attempt to link the phenomenon of mistuning to the notion of bitonality invokes a controversial issue. He attempts to solve this dilemma by explaining, especially in contrapuntal contexts, that "it is not a question of two equally important tonalities but a parallel between one dominating tonality and a secondary tonality which is complementary to the first, colouring it and veiling it over" (Kárpáti 1975, p.161; see also p.169). Bartók himself commented on the problem of bitonal/polytonal identification:

Polytonality exists only for the eye when one looks at such music. But our mental hearing [...] will select one key as fundamental, and will project the tones of the other keys in relation to the one selected. The parts in different keys will be interpreted as consisting of altered tones of the chosen key.[...] Our hearing cannot perceive two or more different keys with two or more different fundamental tones, as such; it will simplify matters by reducing the maze of keys to one principal key (Bartók 1976, Harvard Lectures, p. 365-367).

Kárpáti's polytonal assumptions do yield some significant structural insights, however. In the finale of the Fifth String Quartet, he informs us that the bitonal relation (A major/Bb major) in the diatonic melody of the Allegretto con indifferenza (Ex. 7a) is already contained in the "organic" structure of the original mistuned theme (Ex. 7b), thereby proving "that these kinds of structural mistuning usually have bitonality concealed somewhere within them." He infers

\footnotetext{
${ }^{5}$ See also Bartók, Rumanian Folk Music, Vol. IV, 18-20, especially the scale patterns of Table 2 in which an arrow indicates the raising or lowering of the fifth degree $(G)$.
} 
the same bitonal principle in the linear manifestation of the closing, mistuned scale-motif (Ex. 7c). However, whereas the scalar form in the coda of the movement (mm. 763ff.) Ex. 7a, the final scalar variant (Ex. 7c) revises the relation of the two component tetrachords from a transpositional (E-F\#-G\#-A/Bb-C-D-Eb) to inversional (B-C-D-E/F-G-A-Bb) one. Thus, the lack of transpositional equivalence between these tetrachords and the larger scalar symmetry, which is confirmed by the literal inversional form of the upper tetrachord (F-G-A-Bb) in the lower strings (Eb-Db-Cb-Bb), precludes any visual or aural perception of more than one tone center because of the organization of the entire symmetrical conglomerate around the single axis of $\mathrm{Bb}-\mathrm{Bb}^{6}$.

Example 7: Kárpati's interpretation of bitonality and mistuning in Bartók's Fifth String Quartet

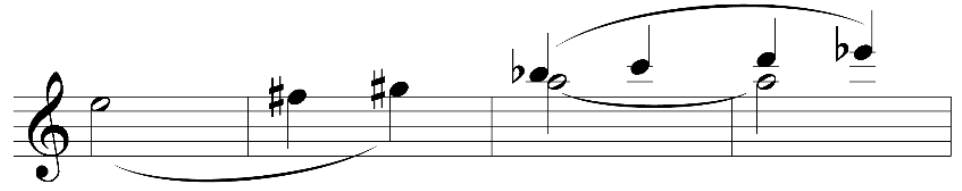

Example 7A: Kárpati's Example 145: Bitonal relation (A major/ Bb major) in the diatonic melody of the Allegretto con indifferenza of Movement 5
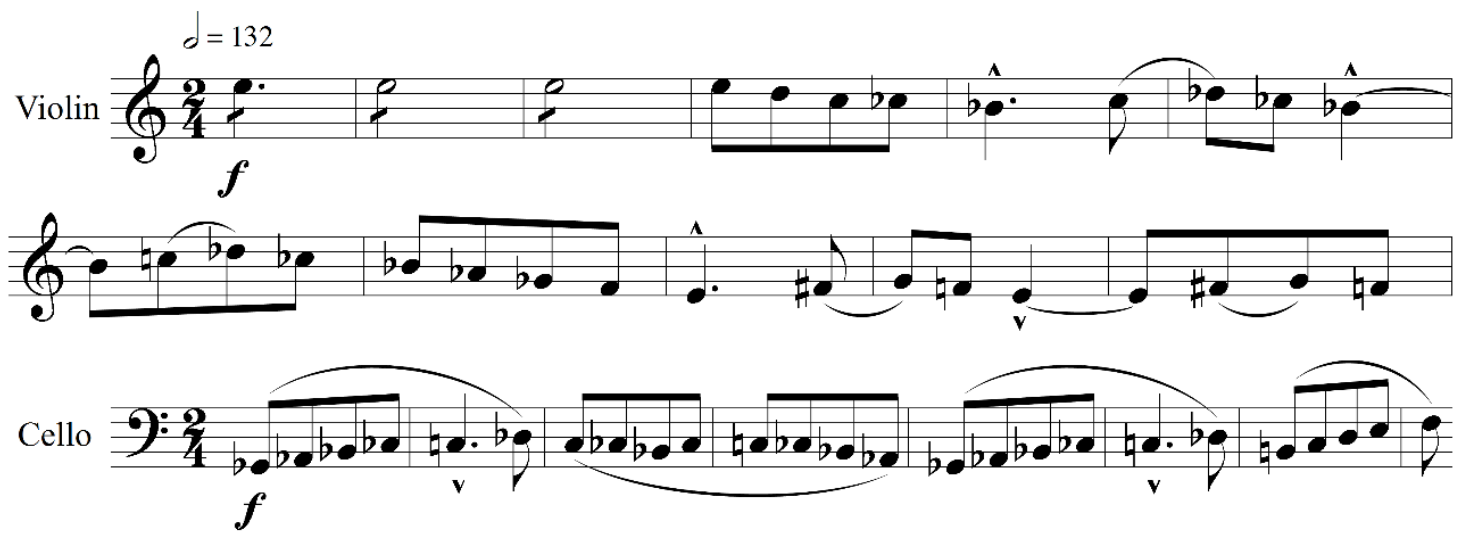

Example 7B: Kárpati's Example 223: Original mistuned theme of Movement 5, mm. 14ff., violins, and mm. 55ff., violoncello

\footnotetext{
${ }^{6}$ Further reference is made to Kárpáti's tonal/modal conception of this passage in the discussion of Malcolm Gillies's theory of pitch notation, below.
} 


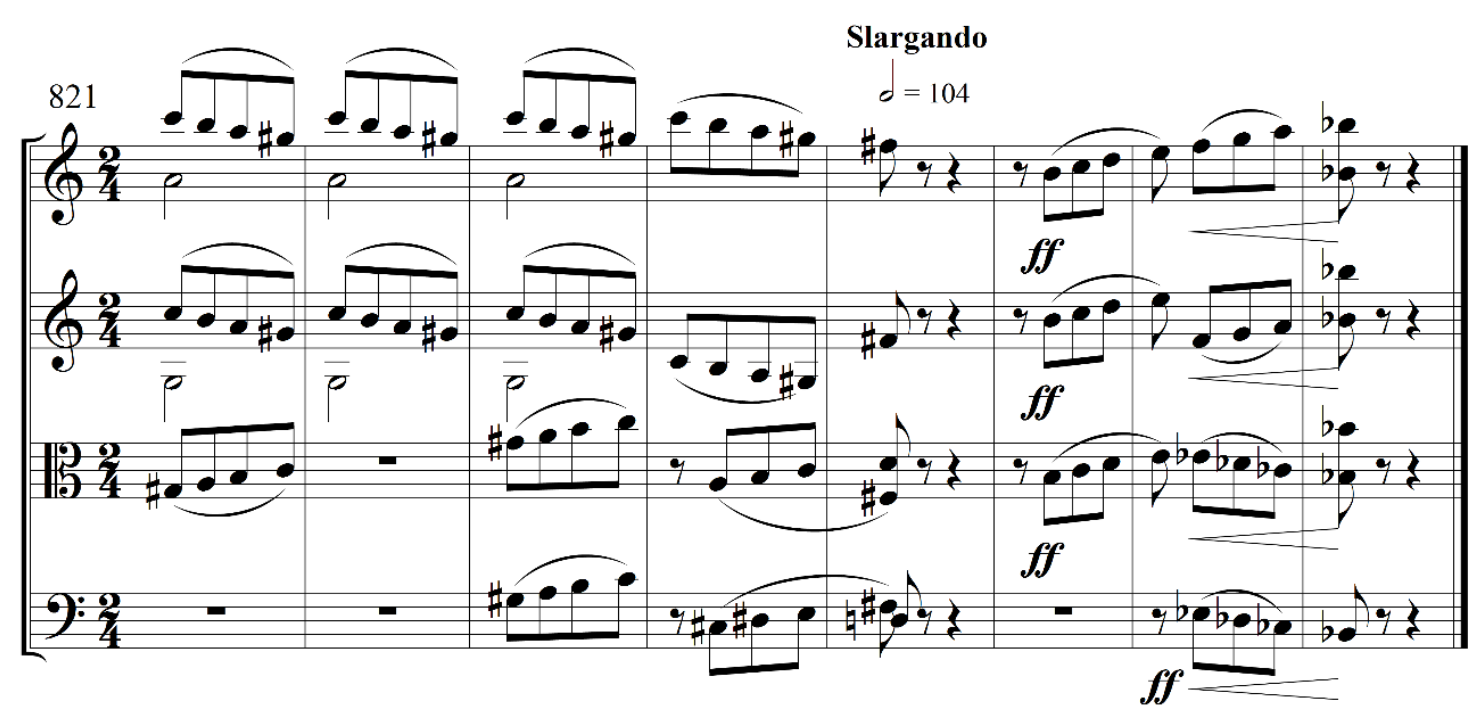

Example 7C: Closing mistuned scale-motif of Movement 5, mm. 826-8, violins

\section{5 - Pentatony, Modality, and Polymodal chromaticism}

One of the means by which Bartók was to transform the diatonic modes of folk music into an extreme chromaticism was by simultaneous combination of two or more of these modes on a common tonic, which he referred to as "polymodality" or "polymodal chromaticism" (Bartók 1976, "Harvard Lectures" p.367) $)^{7}$. However, to discover that chromaticism is produced by polymodal combination in one passage or work is not to establish a universal principle for the chromatic relations in his music; in many of his compositions, chromaticism is so far removed from any modal source that it can only be considered on its own abstract terms. Bartók himself referred to a "new" chromaticism that he invented in 1923 in his Dance Suite (Bartók 1976, "Harvard Lectures" p. 379), which was influenced by Arab melodies from Northern Algeria, which were known to him since 1913: "the single degrees generally are at a half-tone distance from each other; thus, they cannot be regarded as ingredients of various modes" (Bartók 1976, "Harvard Lectures" p. 377). He stated further that his "second attempt was made in 1926; on that occasion I did not try to imitate anything known from folk music" (Bartók 1976, "Harvard Lectures" p. 380). He then pointed to the Fourth String Quartet (second movement), Cantata Profana (fugue theme), Music for

7 Edwin von der Nüll, in Béla Bartók: Ein Beitrag zur Morphologie der neuen Musik (Halle: Mitteldeutsche Verlags A.G., 1930, p. 74), appears to have been the first to discuss this principle in Bartók's music, in which combined Phrygian and Lydian modes on a common tonic produce the entire chromatic continuum. 
Strings, Percussion, and Celesta, and other works, as examples of this "new" chromaticism.

In spite of Bartók's "new" chromatic category, which is so fundamental to the language of the Fourth String Quartet, Colin Mason argues in favor of a polymodal interpretation of the chromatic materials (Mason 1957, p. 195). He contends that the opening four measures function as an introduction in which implied segments of the traditional diatonic modes are based on a common tone (C). His polymodal interpretation includes many modes within the single tonality of C (Ex. 8), adding that the tonal implications of the polymodal introduction are fulfilled gradually in the course of the work and that these subsequent tonal events implied in the introduction are part of the gradual growth of the work into the key of $\mathrm{C}$. Although there is some tendency in the last two movements toward nonsymmetrical (quasi-modal) thematic material, Mason's reference to the theme in the fourth movement (va, mm. 6ff.) as "Lydian" with lowered seventh degree disregards a fundamental contextual characteristic of this theme, namely, the combination of diatonic and octatonic sets that form this Romanian nondiatonic mode. Each of these two pitch-sets is manifested in its complete form at crucial points in the movement (Antokoletz 1982, p. 236-238). The octatonic collection becomes increasingly prominent in the remainder of the quartet; e.g., the main theme of the fifth movement (mm. 15-18), a segment of the octatonic scale, appears later in its complete octatonic form (mm. $47 \mathrm{ff}$.).

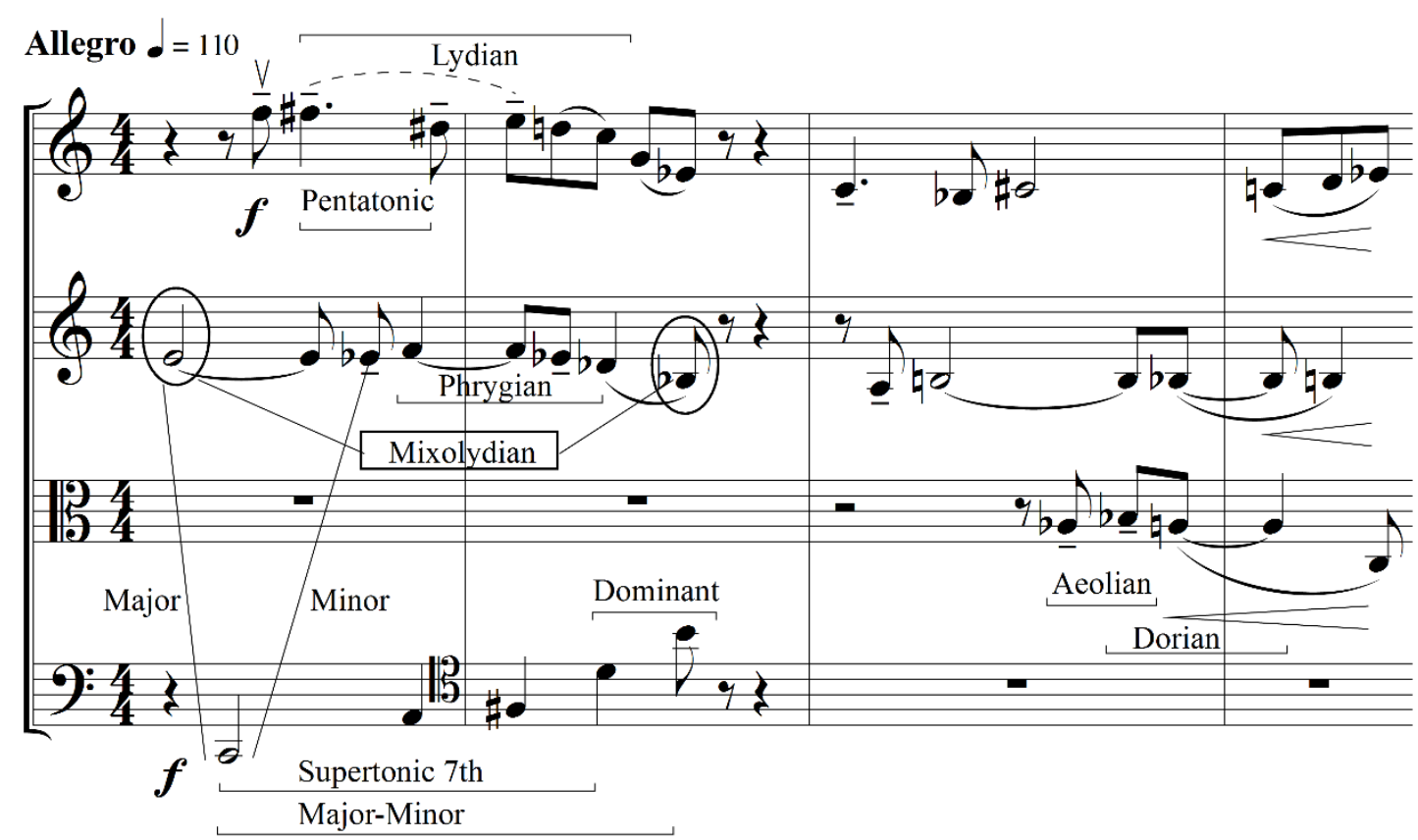

Example 8: Polymodal interpretation by Colin Mason of the opening four measures of the Fourth String Quartet 
One may agree with Mason that many of the pitch collections in the quartet are related to segments of the opening four measures, but one must dispute such assumptions that, e.g., the E and Bb of vn II (mm. 1-2) imply in this context the third and seventh degrees of the Mixolydian mode based on $\mathrm{C}$, especially since diatonic collections having pitch-class priority are irrelevant to the quartet. In addition, ambiguities arise when Mason refers to $\mathrm{Ab}$ and $\mathrm{Bb}$ in va (at m. 3) as the sixth and seventh degrees of the Aeolian mode, since these tones can also be the sixth and seventh degrees of the Phrygian mode or various degrees of other modes on $\mathrm{C}$.

Mason assumes that "polymodality" was Bartók's final solution of the problem of total chromaticism, i.e., "a multiplicity of simultaneous modes on a common tonic." (Mason 1957, p. 195). While Bartók's own writings acknowledge this principle (Bartók 1976, "Harvard Lectures" p. 365-375), each individual composition from a different style period of Bartók's career must be considered on its own terms. For instance, the Fourth Quartet ultimately contains numerous formations (symmetrical and nonsymmetrical) that do not correspond to the traditional diatonic modes. In contrast, such works as the Concerto for Orchestra include extensive occurrences of complete modes, either separately or in polymodal combination, and their transformation into more abstract symmetrical (cyclic-interval) formations ${ }^{8}$.

\section{6 - Pitch-Class Set Theory, Atonality, and Latent serialism}

In his essays, Bartók differentiated between atonality, polytonality, and polymodality, stating that "in a final word on this subject, we may say that atonal music offers no fundamental tone at all, polytonality offers - or is supposed to offer - several of them, and polymodality offers a single one. Therefore our music, I mean the new Hungarian art music, is always based on a single fundamental tone, in its sections as well as in its whole. [...] Polymodality is to be found especially in my works" (Bartók 1976, "Harvard Lectures" p. 370-371). Yet, several theorists have espoused the notion of atonality in varying degrees in Bartók's music, often according to the types of pitch constructions used.

Allen Forte attempts to show that the third movement of the Fourth String Quartet is produced by Bartók's use of a unique system that resembles a "serial schema" (Forte 1960, p. 233-45). According to Forte (1960, p.234), two whole-tone trichords of mutually exclusive pitch-class content may be combined to generate

\footnotetext{
${ }^{8}$ Polymodal chromaticism, as one of the techniques for transforming the diatonic folk modes into abstract symmetrical pitch constructions, is essential to my own theoretical approach, some of the principles of which are discussed below.
} 
three species of hexachords: whole tone, diatonic, and chromatic (Ex. 9). In this serial schema, the two whole-tone hexachords are axial (subgroup I), and six diatonic hexachords (subgroup II) are built up from the six notes of whole-tone hexachord WX. (Each note of WX is the "root" or lowest note of each of these diatonic hexachords.) The six complementary diatonic hexachords (subgroup III) are built up correspondingly from the tones of whole-tone hexachord YZ. In addition, WY and XZ form two complementary chromatic hexachords.
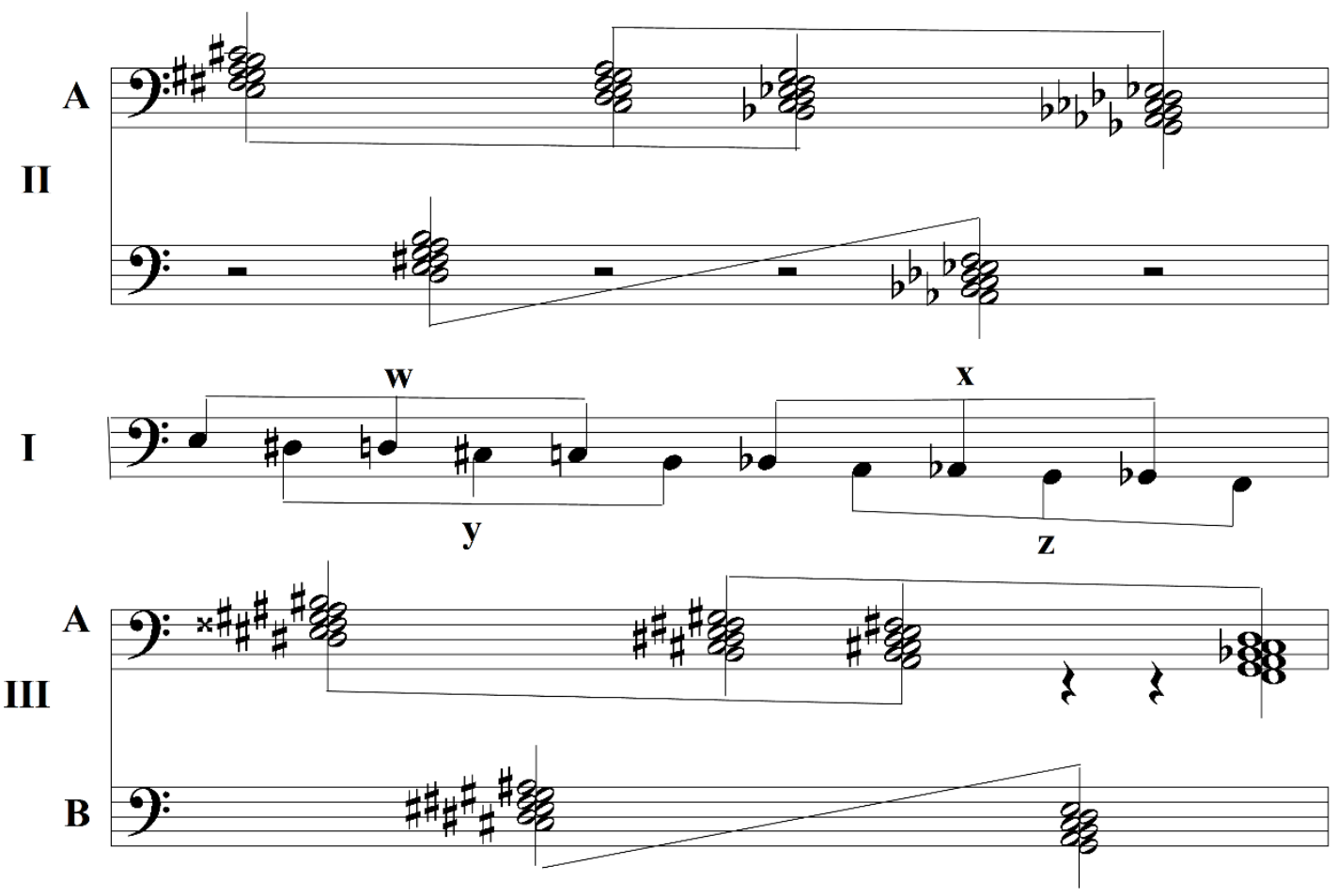

Example 9: Forte's "serial schema" based on three species of hexachords, Mov. III of the Fourth String Quartet

For Forte, trichordal complementation is essential for expansion through the system. His analysis (summarized in Example 10) outlines hexachordal progression through the entire movement (Forte 1960, p. 235). His main thesis is that a specific hexachord (diatonic A-G-F/E-D-C) predominates, since it unfolds as a "cantus firmus" in the lowest notes of the changing pedal chords: A in vn I (mm. 4-13); G in va (mm. 13-21); F (mm. 22-31); E (mm. 32-33); D (mm. 33-34); and $C$ in vc (mm. 34-40). Forte states that the lower trichord, C-D-E, because of its temporal position in the "cantus firmus," is allowed maximal association with other trichords. Perhaps he means that by the time C-D-E occurs at the beginning of the middle section (mm. 32-40), its complementary trichords have already 
unfolded, and these, when viewed together with C-D-E, produce the three hexachordal species. We can only surmise this from his statement that "a relation ... that further integrates the work around the C trichord, is expressed (at m. 32) by the $\mathrm{B}$ trichord. This element, in addition to complementing the $\mathrm{C}$ trichord chromatically, connotes the F trichord via the axial whole-tone hexachord $\mathrm{YZ}$ and thus doubly supports the continuity of the cantus firmus" (Forte 1960, p. 237).
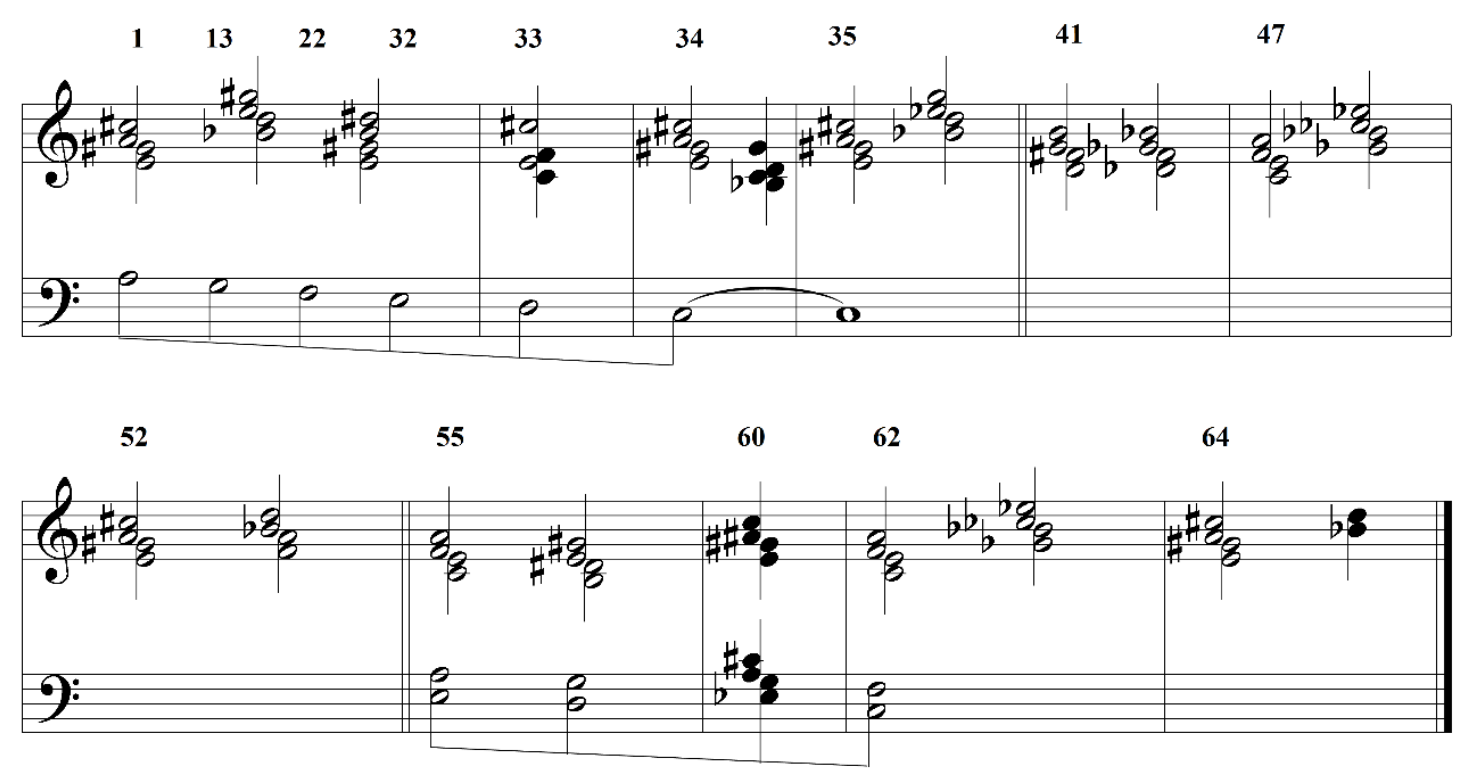

Example 10: Forte's summary of hexachordal progression through the entire third movement of the Fourth String Quartet.

(For convenience, Forte presents only the boundary intervals of the trichords)

Forte's assumptions regarding maximal trichord association with the basic C-D-E seem improbable. He presents his theory of maximal trichordal association beginning with the first trichord (A-G-F) of the "cantus firmus." At $\mathrm{mm}$. 1-13, his direct association of one of the two pedal trichords (A-B-C\#) with the first "cantus firmus" trichord (F-G-A) to give us a larger incomplete wholetone hexachord is unconvincing, since they appear on different contextual levels; A-B-C\# is part of the local pedal chord, while the tones A-G-F of the "cantus firmus" trichord separately unfold over a longer period of time. The tones of both these trichords therefore do not occur together at any point in this first large section of the movement (mm. 1-34). For instance, when A moves to $G$ in va (m. 13), only the boundary interval, A-C\#, appears in the pedal chord. Trichords and hexachords do have a function to some degree in this movement, but Forte, in his 
"serial schema" (Ex. 9), attempts to force a large number of diverse formations into a theoretical interpretation that is incompatible with the musical context.

Another approach using Forte's atonal pitch-class sets and terminology is seen in Richard Cohn's notion of transpositional processes (Cohn 1988). Cohn acknowledges that the principle of inversional symmetry (IS) as proposed by other theorists plays some role in Bartók's music, but he asserts that this principle can also be interpreted according to what he calls transpositional combination (TC) ${ }^{9}$. His argument in favor of the competing "TC" principle is based on the notion that the local contour of a literal inversional design is necessary for validating the "IS" interpretation of a given symmetrical pitch collection. This notion and his statement that "all of the inversionally symmetric set-classes favored by Bartók share another property as well: [that] each may be generated by transpositional combination," (Cohn 1988, p. 23) are equally problematical. There seems to be no relevance in mentioning the self-evident TC-property inherent in all symmetrical formations any more than one would need to describe triads in a traditional harmonic progression as vertical stackings of major and minor thirds.

The primacy of any given principle ("TC," "IS," or otherwise) must be determined by the immediate context. Let us take one pertinent instance. Cohn questions the consistency of my own reference to the octatonic scale (D-E-F-GG\#-A\#-B-C\#) in Bartók's Fourth String Quartet as the simultaneous product of two inversionally symmetrical tetrachords (D-G-G\#-C\# and E-F-A\#-B) and of TC. We may state simply that both conceptions are relevant depending on the particular context. In the first movement, when cell Z (G\#-C\#-D-G, or D-G-Ab-Db, in va and vn $\mathrm{I}$, at $\mathrm{m} .22$ ) returns in the same permutation (interval 5-1-5) at a new pitch level (B-E-F-A\#, opening of the development, mm. 52ff.) we see that the transpositional relation is intended - this is analogous to the transposition of the tonic triad to that of the dominant toward the end of the exposition in a traditional tonal piece (Antokoletz 1982, p 118-119). In the same passage of the quartet (m. 57), vc and vn I play the original $Z$ cell (G\#-C\#-D-G) now in its permutation (C\#-D-G-Ab) around a new axis (E-F) established by the transposed $Z$ cell (B-E-F-A\#), so we can say that the symmetrical rather than transpositional relation is intended now between the two $\mathrm{Z}$ transpositions. In the second movement of the quartet, both $\mathrm{Z}$ transpositions are combined to form the octatonic scale, D-E-F-G-G\#-A\#-B-C\# (va, mm. 243-6), appearing not in their explicit transpositional relation, but rather in their symmetrical one (D-G-G\#-C\# and E-F-A\#-B) around the axis of symmetry, G-G\#.

Thus, while both theoretical principles ("TC" and "IS") are relevant in the quartet, it is the "IS" relation that serves to articulate the new "tonal" area (i.e.,

\footnotetext{
${ }^{9}$ Cohn's definition states that "Any pitch- or pc-set has the TC-property if it may be disunited into two or more transpositionally related subsets;" (Cohn 1988, p. 23).
} 
axis of symmetry) of each section of the sonata-allegro structure. The transpositional relation plays more of a transitional role between them. The relevance of "IS" (as opposed to "TC") may be illustrated by way of analogy to traditional tonal music: in a I-IV-V-I progression, it is the tonally functional voiceleading of the major triads rather than their transpositional relation that is primary.

\section{7 - Nontraditional Tonal System Based on the Interval Cycles and Inversional Symmetry}

An entirely different set of principles is found in a system referred to by George Perle as twelve-tone tonality (Perle 1977) ${ }^{10}$. This system is based on the joining of the concepts of the interval cycle and inversional symmetry. These concepts can be traced to the music of Debussy, Berg, Webern, Bartók, and others. Twelve-tone tonality refers to the establishment of tonal centricity (based on the concept of an axis of symmetry) through operations upon inversionally related interval cycles, analogous to the major and minor scales in traditional tonal music $^{11}$.The basic premises of twelve-tone tonality are contained within two cyclicinterval arrays (Ex. 11).

Example 11: Basic premises of Perle's system of "twelve-tone tonality", as seen in the joining of the concepts of the interval cycle and strict inversional symmetry

\footnotetext{
${ }^{10}$ Basic stages of this system appear earlier in Perle's article, "Symmetrical Formations."

11 In contrast to Perle's premises based on pitch-class symmetry, Berry, in his "Symmetrical Interval Sets," employs concepts of symmetry primarily based on pitch-set types and only secondarily on pitch-class set types, whereas Jonathan Bernard, in his "Space and Symmetry in Bartók," Journal of Music Theory 30/2 (1986): 185-201, rejects the principle of pitch-class symmetry in his analyses. Bernard's notion of pitch and registral symmetry, which seems almost "Webernist," is irreconcilable with Bartók's own compositional orientation, as suggested in the composer's own essays, and seems, therefore, to be fortuitous in Bartók's music in general. Bartók's approach in terms of thematic, phraseological, and contrapuntal design, despite his modal/symmetrical approach to melodic and harmonic construction, belongs more to traditional notions than to the world of Webern, Stockhausen, and Xenakis. Registral symmetry does not seem to be any more applicable to Bartók's music than it does to the music of Haydn, Mozart, or Beethoven.
} 


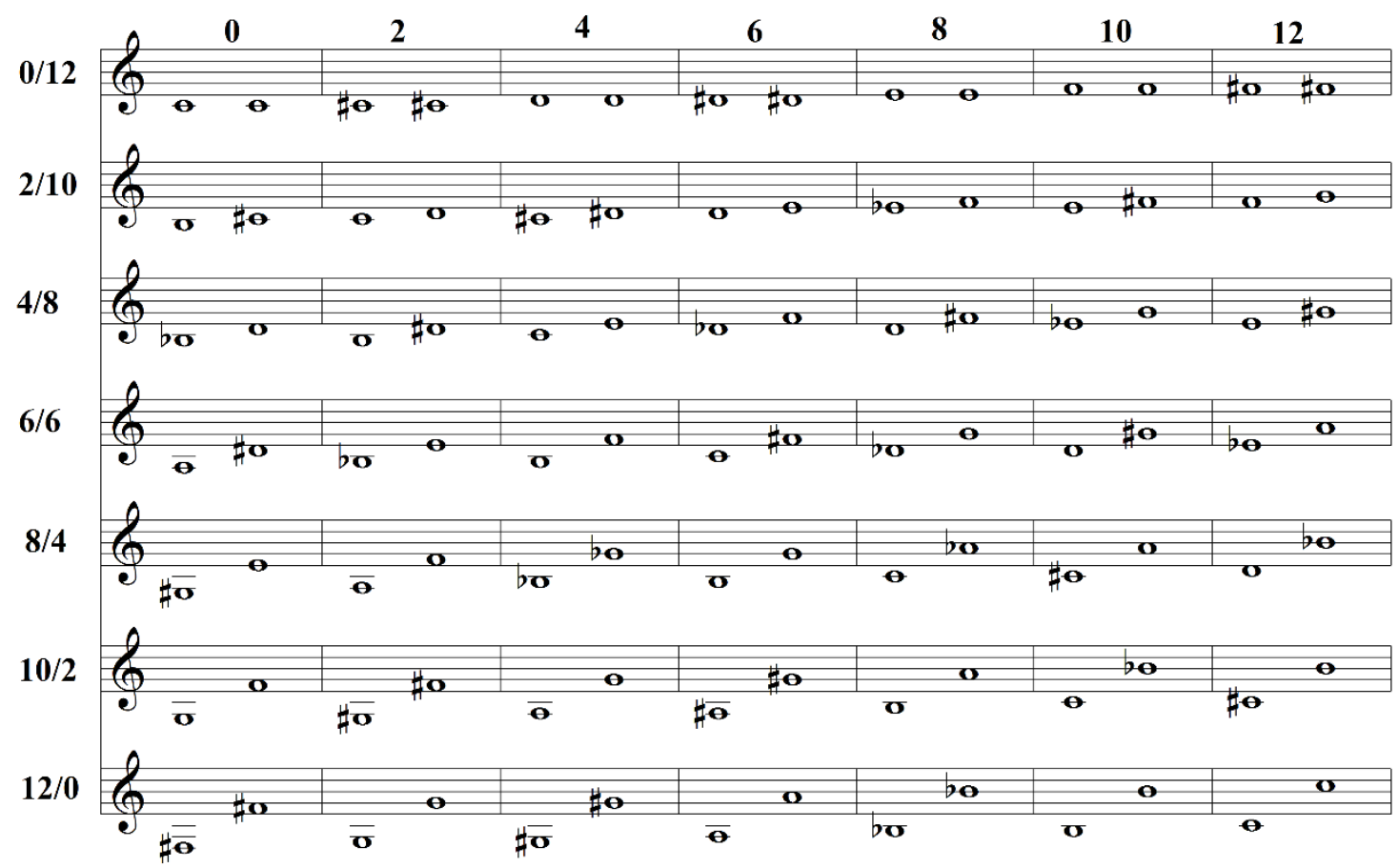

Example 11a: Even-sum (Axis) and Interval Array

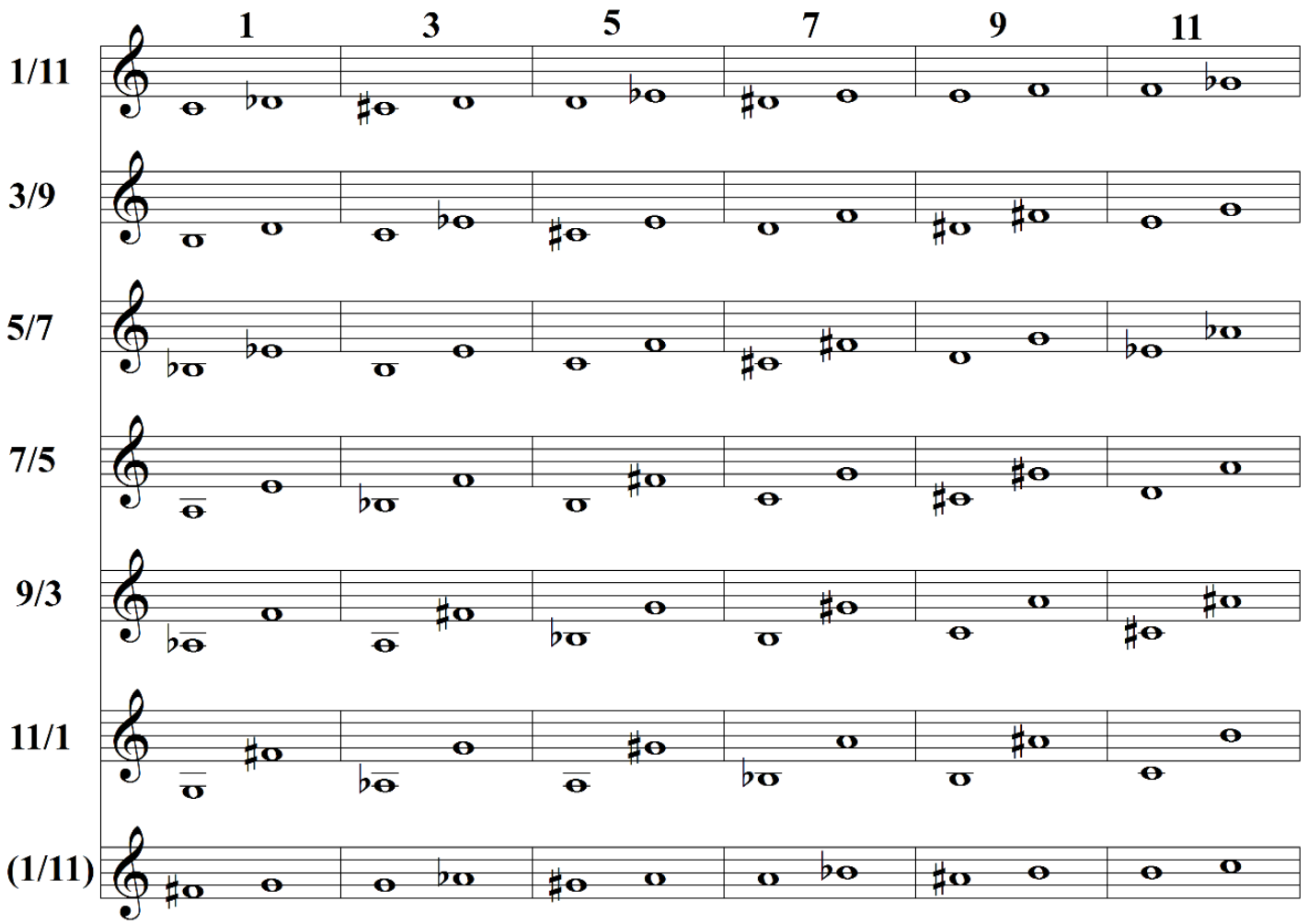

Example 11b: Odd-sum (Axis) and Interval Array 


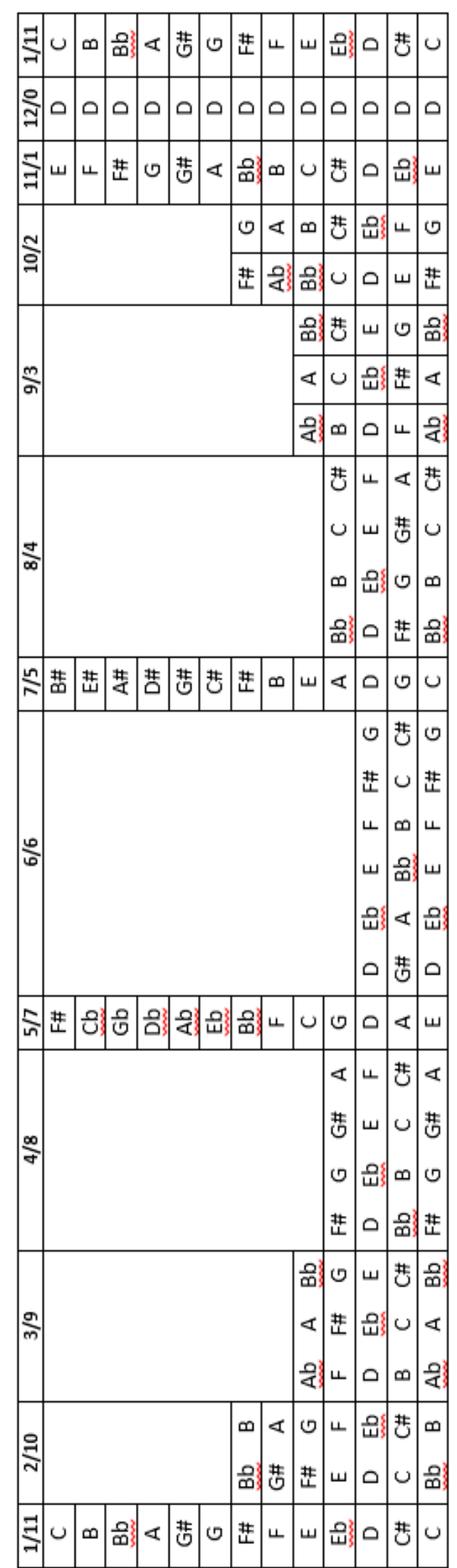

Example 12: Entire System of the Interval Cycles of Antokoletz

\section{MUSICA THEORICA}

Revista da Associação Brasileira de Teoria e Análise Musical Journal of the Brazilian Society for Music Theory and Analysis 
My own approach to Bartók's musical language explores principles of inversional symmetry in connection with the entire system of the interval cycles (see Ex. 12) and the ramifications of these principles as they evolved from and interact with the folk modes ${ }^{12}$. The fusion of both concepts (the interval cycle and strict inversional symmetry) was to be rigorously systematic in many of Bartók's later works, especially the Fourth and Fifth String Quartets (1928 and 1934) and Music for Strings, Percussion, and Celesta (1936).

Study of No. 133 ("Syncopation") from the Mikrokosmos reveals how both traditional (diatonic) and nontraditional (cyclic-interval) pitch constructions are absorbed into a scheme of symmetrical relations. The piece exemplifies Bartók's synthesis of two opposing concepts of tonal priority, based on the juxtaposition of triadic and symmetrical constructions (Ex. 13). The opening G-major triad is reiterated against an unfolding (symmetrical) chromatic tetrachord, Eb-E-F-F\#. Addition of a held $\mathrm{Bb}$ at the first cadential point transforms the G-major triad into a "polymodal" major-minor symmetry, G-Bb-B-D. (Bartók states that "not only different modes can be superposed; the same can be done with the common major and minor scale or, to be more exact, with a major and minor pentachord. As a result, we will get a triad with a doubled third; one minor, the other major.") (Bartók 1976, "Harvard Lectures" p.368). The latter now forms a symmetrical relation with Eb-E-F-F\# around the same axis of symmetry, either E-F or Bb-B (Ex. 13b). All of the symmetrically related dyads of Ex. 16b (E-F, Eb-F\#, D-G, and $\mathrm{B}-\mathrm{Bb}$ ) can be found in the sum-9 column of Perle's Odd Array (Ex. 11b).

Example 13: Antolotetz's analysis of Bartók's № 133 (Syncopation) from the Mikrokosmos, based on symmetrical transformation of the traditional G-major modal triad

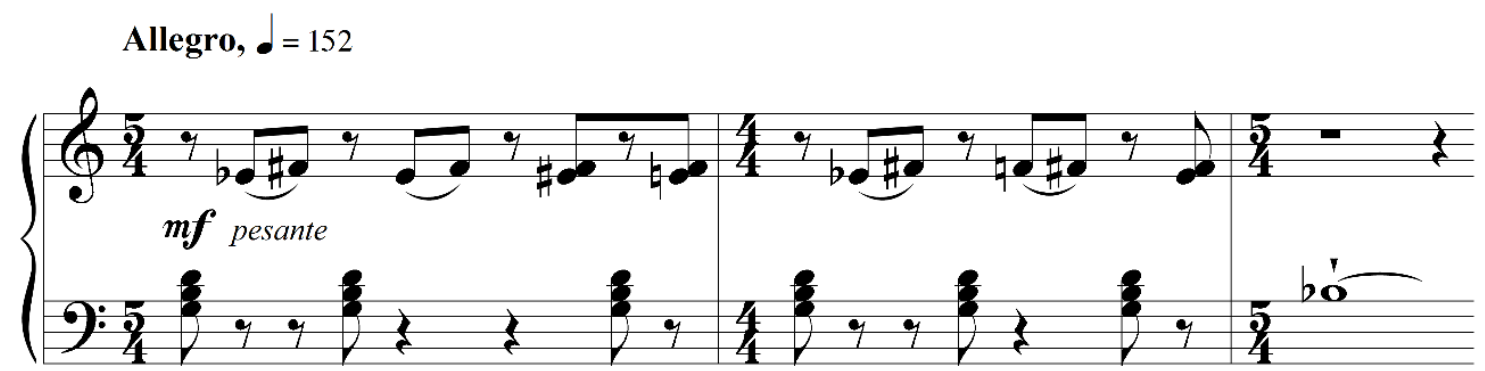

$s \boldsymbol{f f}$

Example 13a: $\mathrm{mm} .1-3$

12 See Antokoletz (1977), The Music of Béla Bartók, the basic principles of which were presented earlier (1975) in his dissertation, "Principles of Pitch Organization"; an extract of the latter was published in In theory Only 3/6 (September 1977) p. 3-22. 


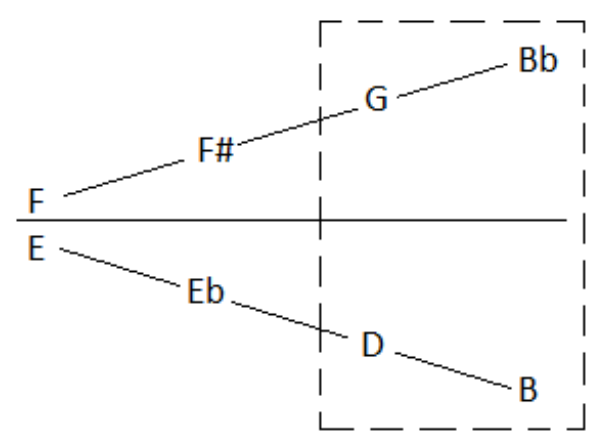

Example 13b: Symmetrical relation of G-major-minor to chromatic tetrachord Eb-E-F-F\#

The interval cycles and their derivative symmetrical segments (cells), analogous to the triadic harmonies derived from the major and minor scales in traditional tonal music, pervade many of Bartók's works. Of all of Bartók's works, the Fourth String Quartet contains the most comprehensive and systematic interaction of symmetrical cells. The four-note symmetries $\mathrm{C}-\mathrm{C} \#-\mathrm{D}-\mathrm{Eb}$ and $\mathrm{Bb}-\mathrm{C}$ D-E are two of three basic cells $\left(X, Y\right.$, and $Z$ ) in the quartet ${ }^{13}$. While $X$ and $Y$ are segments of uni-intervallic cycles, cell Z, G\#-C\#-D-G, is a compound cyclic tetrachord consisting of two tritones, a property which permits it to be permuted around either of two axes of symmetry (one of these is represented by either C\#D or G-G\#, the other implicitly by E-F or Bb-B) (Antokoletz 1982., p. 71-72). This special double-tritone tetrachord (cell Z) is part of a symmetrical interaction that establishes the basic axes of symmetry within the structure of the sonata-allegro form of the first movement. For instance, Bartók uses two transpositions of the same symmetrical chord (G\#-C\#-D-G and B-E-F-Bb) as a way of pivoting between two axes of symmetry a minor third apart (C\#-D and E-F). Example 14a shows one of these transpositions (G\#-C\#-D-G) progressing symmetrically to a permutation of the other (Bb-B-E-F) around the common axis of C\#-D (or G-G\#). In Ex. $14 \mathrm{~b}$, both chords are rotated so they again progress symmetrically from one to the other, but around a new common axis of E-F (or Bb-B). The idea here is that progression between two different "tonal" areas (axes) can be produced by

\footnotetext{
${ }^{13}$ Perle first referred to the chromatic tetrachord as "set X," and the whole-tone tetrachord as "set Y," in "Symmetrical Formations" (1955). Leo Treitler first referred to the double-tritone tetrachord as "cell Z," in "Harmonic Procedure in the Fourth Quartet of Béla Bartók," Journal of Music Theory $3 / 2$ (November 1959) p. 292-8, as a follow-up to Perle's designations of sets X and Y. Antokoletz was the first to show, then, how all three cells were part of a larger system in the Fourth Quartet, in his dissertation, "Principles of Pitch Organization" (1975), and in a larger body of Bartók's music, in The Music of Béla Bartók (1984). (The $\mathrm{Z}$ nomenclature is not to be confused with that in the theoretical writings of Allen Forte.) Earlier, Milton Babbitt, in "The String Quartets of Bartók," Musical Quarterly 35 (July 1949) p. 377-85, had pointed to the unity of purpose in the quartets by showing some significant functions of intervallic structures with analogical references in traditional tonal functions.
} 
means of common chord pivots, a principle essential in traditional changes from one key to another. Examples 14c and 14d show how both tetrachords belong simultaneously to two different pairs of inversionally related cycles that converge at the two pairs of dual axes, C\#-D or G-G\# (Ex. 14c) and E-F or Bb-B (Ex. 14d). This kind of symmetrical modulation based on cell $\mathrm{Z}$ is evident in many of Bartók's works, especially since the Fourth Quartet in $1928^{14}$.

(a) Sum-3 axis: C\# D (or G-G\#)

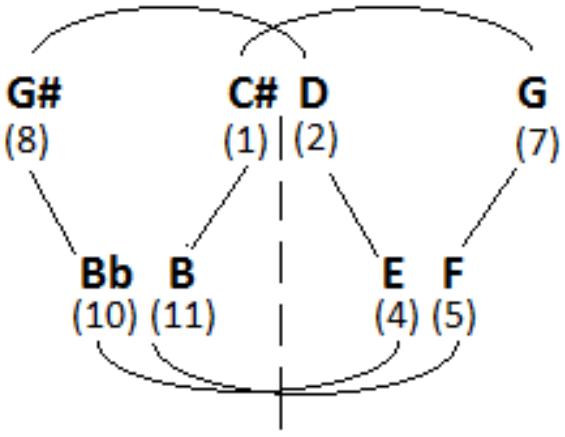

(c) Sum-3 (=15) aligment of inversionally related semitonal cycles (b) Sum-9 axis: E-F (or Bb-B)

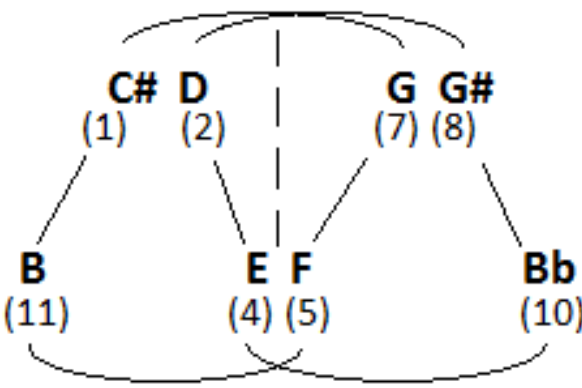

(d) Sum-9 (=21) aligment of inversionally related semitonal cycles pc nos: $2 \quad 3 \quad 4 \quad 5615$ $\begin{array}{llllll}1 & 0 & 11 & 10 & 9 & 8\end{array}$

$$
\left.\left(\begin{array}{lll}
D & \text { eb } & e \\
C \# & c & b
\end{array}\right]_{b b}^{f}\right]_{a}^{f \#} \quad G \quad G \#--\cdot-
$$

$$
\left.\left.\left(\begin{array}{ccc}
F & f \# & g \\
E & e b & d
\end{array}\right] \begin{array}{l}
g \# \\
c \#
\end{array}\right] \begin{array}{lll}
a & B b & --. \\
c & B & --.-
\end{array}\right)
$$

$\begin{array}{llllll}5 & 6 & 7 & 8 & 9 & 10 \\ 4 & 3 & 2 & 1 & 0 & 11\end{array}$

Example 14: Fourth String Quartet, Mov. I, abstract symmetrical chord (G\#-C\#-D-G) and its minor-third transposition (B-E-F-Bb), that is, two equivalent double-tritone tetrachords, each derived from the principal tones - tonic, fourth, and seventh degrees, e.g., Ab-D-G (in enharmonic spelling, G\#-[ ]-D-G) - of the Slovak Lydian mode. Given $C=0, C \#=1, D=2 \ldots C=12$ (or 0$), C \#=13$ (or 1 ) $\ldots$ etc, the axis of symmetry is conveniently represented by the sum of any two notes that are equidistant from the imaginary line in either (a) or (b) above

${ }^{14}$ See Antokoletz 1982, especially Chaps. V ("Construction, Development, and Interaction of Intervallic Cells") and VI ("Tonal Centricity Based on Axes of Symmetry"). 


\section{7 - Conclusion}

This study has addressed some of the conceptual problems that have existed in determining the primary means of pitch organization in Bartók's music. Since Bartók's transformations and syntheses are based on a multiplicity of divergent modal and chromatic constructions, the foregoing critique as well as a more comprehensive study of the various theoretic-analytical approaches discussed herein can contribute to a more meaningful interpretation of Bartók's musical language and a deeper appreciation of his aesthetics.

\section{References}

1. Antokoletz, Elliott. 1975. Principles of Pitch Organization in Bartók's Fourth String Quartet. Ph.D. diss., City University of New York.

2. 1982. The Music of Bartók: Some Theoretical Approaches in the USA. Studia musicologica 24, p. 67-74.

3. Bartók, Béla. 1976. Béla Bartók Essays, ed. Benjamin Suchoff. New York: St. Martin's Press.

4. Cohn, Richard. 1988. Inversional Symmetry and Transpositional Combination in Bartók. Music Theory Spectrum, p. 19-42.

5. Forte, Allen. 1960 (April). Bartók's 'Serial' Composition. The Musical Quarterly $46 / 2$.

6. Gillies, Malcolm. 1989. Notation and Tonal Structure in Bartók's Later Works. New York and London: Garland Publishing, Inc.

7. Kárpáti, János. 1967. Bartók vonósnégyesei. Budapest: Zenemu kiadó.

8. 1975. Bartók's String Quartets. Eng. trans. Fred Macnicol. Budapest: Corvina Press.

9. Lendvai, Erno. 1971. Béla Bartók, An Analysis of His Music. London: Kahn and Averill. 
10. Mason, Colin. 1957 (August). An Essay in Analysis: Tonality, Symmetry, and Latent Serialism in Bartók's Fourth Quartet. The Music Review 18/7.

11. Perle, George. 1977. Twelve-Tone Tonality. Berkeley and Los Angeles: University of California Press.

12. Somfai, László. 1996. Béla Bartók: Composition, Concepts, and Autograph Sources. Berkeley: University of California Press.

13. Travis, Roy. 1970. Tonal Coherence in the First Movement of Bartók's Fourth String Quartet. The Music Forum 2. 